\title{
DE VICIOS Y VIRTUDES EN ALGUNOS TEXTOS CASTELLANOS DEL SIGLO XV
}

\author{
Concepción Salinas Espinosa \\ Doctora en Filología Hispánica
}

Son numerosos los libros de la Edad Media que dedican la totalidad o buena parte de sus páginas al tratamiento de algún asunto de índole moral. Desde los confesionarios a los catecismos, sin olvidar los manuales universitarios, encontramos un sinfín de textos en los que la preocupación por la enseñanza moral se halla presente. ${ }^{1}$ Pero dejando a un lado tanto los escolares como los de carácter religioso, ${ }^{2}$ es nuestro propósito aquí llamar la atención sobre una serie de obras del siglo XV que si bien no pueden ser englobadas en los grupos citados, tratan ampliamente de diversas cuestiones de orden moral.

Entre estas obras destacan en particular aquellas que se ocupan de vicios y virtudes y que van desde las traducciones de los libros de Séneca a los textos doctrinales. ${ }^{3} \mathrm{El}$ tema cuenta con una larga tradición que, partiendo de la época clásica, ${ }^{4}$ fue enriqueciéndose de manera progresiva a medida que los autores que escriben sobre él aumentan el número

1 Tampoco debemos olvidar la literatura sapiencial, pues son abundantes los testimonios de este género en los que se abordan asuntos relacionados con la Filosofía Moral.

2 Sobre el tema de vicios y virtudes en los catecismos y penitenciarios, véase la tesis doctoral inédita de Enrica Julia Ardemagni, «The Influence of Penitencial Documents on Medieval Spanish Literature», D. Ph., Universidad de Wisconsin-Madison, 1985, especialmente las páginas 168-202.

3 Del mismo modo hay un elevado número de composiciones poéticas que versan sobre vicios y virtudes. No hay lugar aquí para ocuparnos de ellas, aunque nos gustaría apuntar algunas como el Decir de las siete virtudes de Francisco Imperial, el Tratado de virtudes e viçios y el Tratado de las quatro virtudes cardinales de Fernán Pérez de Guzmán y el Planto de _las Virtudes e Poesía por la muerte del Marqués de Santillana.

4 Margarita Morreale considera que la sistematización del motivo es de origen estoico y heredado fundamentalmente por los Padres de la Iglesia ( e imitación prerrenacentista de la Divina comedia», en Lengua, Literatura, Folklore. Estudios dedicados a Rodolfo Oroz, Santiago de Chile, Facultad de Filosofía y Educación [Universidad de Chile], 1967, pág. 316). 
de virtudes ${ }^{5}$ que toman en consideración y añaden observaciones acerca de los vicios correspondientes. ${ }^{6}$ De este modo nace uno de los esquemas literarios más productivos de todo el Medievo que también habría de dar frutos en las artes plásticas ${ }^{7}$, pues la oposición virtud-vicio poseía unas inmensas posibilidades dramáticas. ${ }^{8}$ Supone este modelo la simbiosis entre Teología y Filosofía Moral, ya que al clásico sistema de las virtudes se le añadía el correspondiente a los vicios ${ }^{9}$ para indicar a los creyentes de qué debían huir y qué camino era el mejor. Las disertaciones sobre los siete pecados capitales no tenían fines teóricos sino prácticos: servir de guía para la perfección moral y cristiana. ${ }^{10} \mathrm{La}$ creencia se basaba en que las siete virtudes espirituales están alimentadas por los siete dones divinos y siempre se enfrentan a los siete vicios o pecados.

El motivo de las virtudes empleado en textos literarios respondía a cuatro corrientes distintas, según se siguiese a Aristóteles, Séneca, Cicerón o Macrobio. El tratamiento de este tema en Cicerón se halla en el De officiis y en el breve sumario que se incluye en $D e$ inventione. ${ }^{11}$ Las ideas de Cicerón fueron ampliamente utilizadas a lo largo de toda la Edad Media, en concreto las partes de cada una de las virtudes incluidas en la última obra citada. ${ }^{12}$ Esta clasificación se encuentra en la base de lo que luego fue fundamental para establecer el modelo de las cuatro virtudes cardinales. ${ }^{13}$ A partir de los textos de Cicerón, Macrobio elaborará un sistema ético en el que lo importante es el carácter religioso e individual, mostrando más interés por la vida interior que por la activa o exterior. Acepta la existencia de la clásica división en cuatro virtudes (prudencia, templanza, fortaleza y justicia), pero distingue en cada una de ellas cuatro grados diferentes. ${ }^{14}$ El pasaje del Somnium Scipionis de Macrobio dedicado a las virtudes fue ampliamente empleado durante el periodo

5 Frente a la corriente clásica de las virtudes cardinales, durante la Edad Media se alzó el sistema de las siete virtudes espirituales o evangélicas (véase Rosemond Tuve, Allegorical Imagery. Some Mediaeval Books and their Posterity, New Jersey, Princeton University Press, 1966, pág. 88).

6 Para Víctor García de la Concha, el tema recibió un gran impulso a partir del Arbor vitae de San Buenaventura, que propició la multiplicación de diagramas imaginativos sobre vicios y virtudes («Un Arte memorativa castellana», en Serta Philologica F. Lázaro Carreter. Natalem diem Sexagesimum celebranti Dicata, Madrid, Cátedra, 1983, vol. II, pág. 191).

7 Rosemond Tuve señala que el tema de las siete virtudes fue el más popular de la Edad Media en las representaciones artísticas (op. cit., pág. 85).

8 Ibid., pág. 118. No obstante, el esquema de las virtudes ha sido muchas veces asociado al concepto de peregrinación o búsqueda, pues el hombre tenía que actuar como Cristo lo había hecho en la tierra. El tema se -imbricaba fácilmente en otro muy querido para los cristianos: la peregrinación de la vida (ibid., pág. 90).

9 La combinación de vicios y virtudes fue empleado sobre todo a partir del siglo XII: «In the twelfth century the capital vices were sometimes derived from, or at least related to, the four cardinal virtues» (véase Siegfried Wenzel, «The seven deadly sins: some problems of research», Speculum, XLIII (1968), pág. 10).

10 Ibid., págs. 12-13,

11 R. Tuve, op. cit., págs. 61-63.

12 La prudencia, por ejemplo, consta de tres partes: memoria, inteligencia y providencia. Memoria para recordar lo ocurrido, inteligencia para analizar lo presente y providencia para prever el futuro (véase Frances A. Yates, El arte de la memoria, Madrid, Taurus, 1974, pág. 35).

13 Ibid., págs. 34-35.

14 C. S. Lewis, La alegoría del amor. Estudio sobre la tradición medieval, Buenos Aires, Eudeba, 1969, págs. 51-52. 
medieval. ${ }^{15}$ El libro divulgado bajo el nombre de Séneca sobre las virtudes, se convirtió en el manual por excelencia de todo estudiante medieval de Filosofía Moral. Fue uno de los textos más utilizados en el Medievo, del mismo modo que las Éticas de Aristóteles lo fueron en el Renacimiento, en especial la Ética a Nicómaco, que pasó a ser el texto básico para todos los escritores que trataban sobre las virtudes. ${ }^{16}$

Aunque en el tema de las virtudes se siguieron los cuatro autores mencionados, podemos, no obstante, considerar que en la Edad Media triunfaron fundamentalmente dos sistemas: el de Séneca y el de Cicerón con las variantes introducidas por Macrobio. El éxito de este último vino favorecido por el uso que de él hicieron Alberto Magno y Santo Tomás de Aquino, ya que a pesar de manejar otras fuentes, el De inventione de Cicerón les suministra el encuadre básico, sin olvidar por ello las aportaciones hechas por Macrobio. ${ }^{17}$ Este cruce de la tradición ciceroniana con la de Macrobio se produce también en Alain de Lille, aunque en su De virtutibus et de vitiis et de donis Sp. Sancti realizó una importante modificación al modelo establecido por Macrobio al introducir por primera vez las virtudes teologales junto a las cardinales. ${ }^{18}$

Otro de los libros más profusamente utilizados en la Edad Media y relacionado con la tradición senequista en el tratamiento de los vicios y las virtudes es la Formula vitae honestae de Martín de Braga (ca.515-579). Varios de sus escritos son remedos de libros de Séneca, como es el caso de la Formula, epítome del hoy en día perdido De officiis de Séneca. Al igual que había hecho en trabajos anteriores, Martín de Braga eliminó toda concepción teórica del De officiis para entregrar en la Formula vitae honestae, escrita en los últimos años de su vida (entre el 570 y el 579) un manual práctico sobre costumbres sociales. La Formula alcanzó un éxito enorme y llegó a ser una de las obras más leídas de toda Europa, especialmente a fines del período medieval. Paralela al proceso de difusión fue la desaparición de su auténtica autoría, pues la Formula pasó pronto a ser considerada como obra anónima. Más tarde sería atribuida a Séneca con el título de De quattuor virtutibus. ${ }^{19}$ Hasta la llegada del humanismo no se volverá a asignarla a su verdadero autor. ${ }^{20}$ Esto pone de relieve la amplia difusión que este libro alcanzó también entre los escritores renacentistas. ${ }^{21}$

15 R. Tuve, op. cit., pág. 63.

16 Ibid., págs. 60-61.

17 F. A. Yates, op. cit., pág. 94

18 R. Tuve, op. cit., págs. 65-67.

19 Para José Luis Abellán esta falsa atribución es un ejemplo evidente de la cristianización a la que fue sometido Séneca durante toda la Edad Media (Historia crítica del pensamiento español, Madrid, Espasa-Calpe, 1979, vol. I, pág. 353).

20 Karl Alfred Blüher, Séneca en España. Investigaciones sobre la recepción de Séneca en España desde el siglo XIII hasta el siglo XVII, Madrid, Gredos, 1983, págs. 32-35. El interés de los humanistas por Séneca fue manifiesto. Por ello muchas de sus obras son de clara tendencia senequista. También Martín I el Humano y Benedicto XIII mostraron su simpatía hacia la Filosofía Moral de Séneca, llegando incluso a intercambiarse obras de él (véase J. L. Abellán, op. cit., págs. 327-328).

21 R. Tuve señala que ningún autor del Renacimiento preocupado por el tema de las virtudes desconocía este pequeño tratado: «and there can literally be no doubt whatever that Renaissance authors interested in the virtues knew what it said about Prudence, Magnanimity, Continence and Justice» (op. cit., pág. 75). 
Del éxito de la Formula dan buena cuenta las numerosas traducciones que de ella se hicieron a distintas lenguas. En concreto disponemos de dos en castellano pertenecientes al siglo XV. Debemos la primera a Alfonso de Cartagena, sin duda el traductor más importante de Séneca al castellano de esta época. Sus versiones son además las únicas de su tiempo que se basan en los originales latinos. Parte de ellas fueron luego impresas con el nombre de Los cinco libros de Séneca, que se difundieron entre 1491 y 1551 en cinco ediciones. ${ }^{22}$ Lo curioso es que este eminente conocedor de la obra de Séneca no percibiese que la Formula era una obra apócrifa. La tituló Libro de las cuatro virtudes, según aparece en el manuscrito 8830 de la Biblioteca Nacional de Madrid. La otra traducción castellana de la Formula, titulada Las quatro virtudes e doctrinas, se ha conservado en una copia manuscrita del siglo XIX que se encuentra en la Biblioteca Nacional (ms. 20276-13). No debe ser confundida con la de Alfonso de Cartagena, ${ }^{23}$ a pesar de que al final del manucristo se lee la siguiente nota firmada por José Amador de los Ríos:

Esta copia está sacada de la traducción de Alonso de Cartagena, notándose algunas variantes entre el códice del Escorial y el que sirvió para hacer esta traslación. Madrid, 12 de Diciembre de $1846 .{ }^{24}$

Como ejemplo del influjo de la Formula en el siglo XV pueden aducirse los cuatro capítulos de la Visión deleitable del bachiller Alfonso de la Torre ${ }^{25}$ dedicados a las virtudes cardinales, ya que no son más que un buen resumen del pequeño tratado de Martín de Braga.$^{26} \mathrm{El}$ tono de la Formula, que utiliza constantemente la segunda persona para dar las instrucciones relativas a cada virtud, hacía muy fácil la adaptación de ideas a la estructura dialogada de la Visión deleitable. Por supuesto que la personificación de las virtudes, así como la dramatización del contenido que ello supone, no figuran en la Formula; pero no es la primera vez que esta transformación se llevaba a cabo. A principios del siglo XIII, Daude de Pradas traduce en verso el libro de Martín de Braga y amplía considerablemente la obra

\footnotetext{
22 K. A. Blüher, op. cit., págs. 133-134.

23 Ibid., pág. 154.

24 La transcripción, con la modernización de algunas grafías, acentuación y puntuación del texto, es nuestra.

25 En concreto nos referimos a los capítulos $14,15,16$ y 17 de la segunda parte de esta obra (véase la edición crítica de Jorge García López, Salamanca, Universidad de Salamanca, 1991, vol. I, págs. 295-312).

26 También por estos pasajes, además de otros factores estructurales, se ha considerado que la Visión deleitable fue compuesta a imitación del Libro de la Consolación de Severino Boecio. Simina Farcasiu afirma que la Consolación de la Filosofía influye sobre todo en el parlamento entre los personajes Razón y Entendimiento, es decir, en la segunda parte de la obra (en su tesis doctoral inédita, «Castilian Literature and the Religious Orders: A Study of Three Writers», Ph. D., Universidad de Londres [Westfield College], 1985, pág. 137). Pero, creemos, las coincidencias tienen más que ver con el tono general de la conversación entre los dos personajes y con los lamentos de Entendimiento acerca de los males del mundo que con una influencia directa de la obra de Boecio sobre la Visión deleitable. No afecta a unos contenidos puntuales, como sucede en el caso del influjo de la Guía de perplejos de Maimónides o de la Formula vitae honestae de Martín de Braga en la Visión deleitable. Quizá la inspiración del Bachiller se basó en obras intermedias o en el recuerdo de su lectura más que en un apoyo preciso en sus palabras.
} 
al dotarla de estructura alegórica por medio de la personificación de las virtudes y de la introducción de una guía llamada Humildad. ${ }^{27}$

'La tradición medieval en el tema de las virtudes se forjó sobre todo a través de un género, los espejos de príncipes, que le facilitó una extraordinaria popularidad y difusión. En realidad, como ha señalado Carlos Alvar, los espejos de príncipes fueron concebidos como tratados morales que daban cabida a elementos de carácter militar. ${ }^{28}$ La moral cristiana, simplificada en términos de vicios y virtudes, encontró desde principios de la Edad Media el modelo que se adaptaba, o al menos debía adaptarse, al paradigma del hombre virtuoso: el rey. Como apunta María Jesús Lacarra, la figura del príncipe ha sido siempre objeto de especial atención por parte de los moralistas, «sin duda con la esperanza de que el bienestar social podría lograrse por medio de un dirigente bien formado intelectual y moralmente» ${ }^{29} \mathrm{El}$ rey debía ser además religioso y mostrar en su conducta el amor a Dios al actuar en todo momento según sus preceptos. Sólo así Dios podía retribuirle a él y a su pueblo con el bien. En definitiva, el príncipe debía aprender que su misión era la de mantener un comportamiento virtuoso, no sólo para obtener su salvación sino también para facilitar la de sus súbditos. Por eso, en la mayoría de los espejos de príncipes se acaba tratando el tema de las virtudes como el camino que conduce hacia Dios. Muchas de estas obras fueron hechas compilar por los propios reyes para la educación de sus hijos, aunque terminaron siendo libros válidos para la educación de cualquier persona. ${ }^{30}$ Un buen ejemplo es el De regimine principum de Egidio Romano, que llegó a convertirse en modelo del género. ${ }^{31} \mathrm{La}$ glosa castellana de Juan García de Castrojeriz, realizada hacia 1345 , a su traducción del Regimiento de príncipes gozó de una amplia difusión en la Península. Al tema de las virtudes se le dedica la segunda parte del Libro Primero. La glosa de Juan García de Castrojeriz da buena cuenta de la interrelación de las corrientes citadas en un mismo autor:

Mas aquí conviene de notar que estas doce virtudes sobredichas de otra guisa las asigna Macrobio en el su primer libro e el Filósofo en las Éticas. E dice que la prudencia ha seis partes: la primera es razón, la segunda entendimiento, la tercera circunspección, la cuarta prudencia, la quinta doctrinanza, la sexta caución. E Tulio annade dos, pone ocho partes, ca annade remembranza e agudeza para ver lo que ha de facer. (I, II, 3) 32

27 Cesare Segre, «Le forme e le tradizioni didattiche», en Hans Robert Jauss (ed.), La Littérature didactique, allegorique et satirique, Grundriss der Romanischen Literaturen des Mittelalters, vol. VI, Heidelberg, Carl Winter-Universitätverlag, pág. 83.

28 En Carlos Alvar, Ángel Gómez Moreno y Fernando Gómez Redondo, La prosa y el teatro en la Edad Media, Madrid, Taurus, 1991, pág. 103.

29 Cuentistica medieval en España: los orígenes, Zaragoza, Departamento de Literatura Española de la Universidad de Zaragoza, 1979, pág. 35.

30 C. Segre, op. cit., pág. 99 . A pesar del éxito alcanzado durante la Edad Media, la literatura de regimine principum se remonta a la Grecia del siglo IV a. de C., donde era un género que servía para el adoctrinamiento de los jóvenes de familias nobles. Se utilizaba ya el recurso que tanto abundará durante esta época: la enseñanza mediante los consejos dados por un padre, un sabio o un rey a su hijo (véase C. Alvar, op. cit., pág. 102).

31 María Jesús Lacarra, op. cit., pág: 36.

32 Edición de Juan Beneyto Pérez (Madrid, Instituto de Estudios Políticos, 1947, vol. I, pág. 79). 
No obstante, en esta obra, al igual que en la Visión deleitable, se tratan también otros -asuntos relativos a la ética, la economía y la política. En realidad estamos ante un manual que reúne todo tipo de consejos útiles para la vida cotidiana y que sobrepasa el dominio destinado al gobierno de un príncipe, pues se ocupa también de cuestiones más domésticas como pueden ser el «gobierno» de la mujer, los hijos y los siervos. Según afirma Simina Farcasiu, ${ }^{33}$ el De regimine principum de Egidio Romano informa algunos aspectos de la conversación entre Razón y Entendimiento en la segunda parte de la Visión deleitable. ${ }^{34}$ En concreto se refiere a la definición de la vida contemplativa, en cuanto que en las dos obras aparece «cristianizada». La división tripartita de los modos de vida arranca de Aristóteles y la vida contemplativa de la clasificación del Estagirita era fácilmente asimilable a un concepto de vida cristiano. Por eso quizá estemos más ante una simple coincidencia que ante una influencia directa de un autor sobre otro.

Donde sí se aprecia mayor presencia de la obra de Egido Romano es en un espejo de príncipes del siglo XV, en el Doctrinal de príncipes de Diego de Valera:

Pues, descendiendo a la división de las virtudes, Príncipe muy esclarecido, digo que son cuatro maneras de virtudes, según Egidio de Roma escrive en el su conpendio, conviene saber: cardinales, theologales, intelectuales, corporales. Son las cardinales: prudencia, tenprança, fortalesa, justicia; e ovieron este nonbre de cardo, cardinis por quicial, porque estas virtudes son como porta o entrada para todas las otras. Son las theologales: fe, esperança, caridad. Intelectuales son las ciencias especulativas, es a saber: filosofía natural, racional, metafísica, matemátia, geumetría. Corporales son las fuerças del cuerpo, las quales en tanto se pueden llamar virtudes, quanto al exercicio dellas a la virtud se diere, e no más. E las virtudes intelectuales por algunos son nonbradas en otra manera, es a saber: sabiduría, ciencia, entendimiento, prudencia e arte. ${ }^{35}$

No es ésta la única obra de Diego de Valera en la que se trata sobre las virtudes; su Breviloquio de virtudes trata exclusivamente de este tema. En ella se produce el cruce de corrientes entre los diversos sistemas establecidos desde la Antigüedad. Es notoria la influencia de la Formula vitae honestae, que Diego de Valera atribuye a Séneca: ${ }^{36}$

Así digo, muy umano Señor, que a la prudencia conviene, segund sentencia de Séneca, recordar las cosas pasadas e ordenar las pressentes e preveer las porvenir, remediando e proveyendo en ellas quanto el umano juisio basta, por quien él dise: "Qui providus est non dicit: non putavit hoc fieri; quia non dubitat, sed espectat; non

33 Op. cit., pág. 137.

34 «This section [instruction in the House of Reason], and the Vision 's model of ethical instruction as a whole, is also informed by Aegidius Romanus' De regimine principum» (ibid., pág. 137).

35 Edición de Mario Penna (Biblioteca de Autores Españoles, vol. CXVI, Madrid, Atlas, 1959, pág. 191).

36 K. A. Blüher, op. cit., pág. 210. 
suspicatur, sed cavet». ${ }^{37}$ [...] E, decendiendo a la particularidad de las partes de las virtudes ya dichas e a sus difiniciones, digo que la prudencia, segund Tulio tiene ocho partes. [...] La justicia tiene siete partes, segund Macrobio. [...] Según el Philósofo la justicia tiene quatro partes. ${ }^{38}$

En el siglo XV podían aparecer en un mismo autor las cuatro autoridades sobre la materia relativa a las virtudes. En la Repetición de amores de Luis de Lucena también podemos observar la unión de la tradición ciceroniana con la aristotélica:

Donde interviene que daqueste fundamento ha origen todo virtuoso obrar, de las quales nasce assimesmo la honestidad, la qual, segund dize Tulio, en el primero de los Officios, es un accomodado obrar, según la disposición del lugar del tiempo y de la persona con la qual el honbre ha de conversar. Así como Aristóteles en el quarto de la Ethica dize no toda largición ser liberalidad, mas quando conviene, donde conviene, y a quien conviene. ${ }^{39}$

La importancia que se concede al tema de las virtudes a lo largo del siglo XV explica también la proliferación de traducciones de textos sobre este asunto. Cabe destacar al respecto la versión castellana del Fiori di virtù, colección de sentencias y anécdotas morales escrita en Boloña entre 1313 y 1323, que dedica alternativamente un capítulo a un vicio y a una virtud. ${ }^{40}$ La traducción al castellano llegó a tener cuatro ediciones y dos la versión catalana.

Otra prueba del interés despertado en el siglo XV por el tema de las virtudes son las Cuestiones de Filosofía Moral de Alfonso Fernández de Madrigal. En la primera de ellas, titulada «¿Cuál es la más soberana de las virtudes morales?», ${ }^{41}$ el Tostado propone un orden jerárquico de las cuatro virtudes cardinales de acuerdo a su importancia:

37 Palabras tomadas directamente de la Formula vitae honestae : «Nam qui prudens est non dicit: "Non - putavi hoc fieri", quia non dubitat sed exspectat, nec suspicatur sed cavet» (ed. de Claude W. Barlow, Martini Episcopi Bracarensis Opera Omnia, Papers and Monographs of the American Academy in Rome, New Haven, Yale University Press, 1950, pág. 239).

38 Edición de Mario Penna, loc. cit., págs. 147-149.

39 Edición de Jacob Ornstein (Chapel Hill, University of Carolina Press, 1954, pág. 69).

40 C. Segre, op. cit., pág. 106.

41. Esta obra, conocida con este nombre desde la edición de Adolfo de Castro realizada en 1873 (Biblioteca de Autores Españoles, vol. LXV), agrupa dos quaestiones de tema moral pertencientes a dos libros distintos. La referida aquí se incluía en el Libro de las diez qüestiones vulgares; la segunda, titulada «Si la Filosofía Moral es más útil y provechosa que la Filosofía Natural» formaba parte del Libro de las catorze qüestiones. Estos dos libros fueron editados conjuntamente por Luis Ortiz en 1545 en la ciudad de Burgos. El primero estaba dedicado a quaestiones que trataban asuntos mitológicos y el otro se ocupaba de temas de exégesis escrituraria. Los dos se habían editado anteriormente con el Comento al Eusebio, publicado en Salamanca entre 1506 y 1507 por Hans Gysser (véase D. W. MacPheeters, "Influencias del Tostado en Salamanca a fines del siglo XV», en Actas del Séptimo Congreso Internacional de Hispanistas, vol. II, Roma, Bulzoni, 1982, pág. 1091). 
E ansí, paresce de lo suso dicho que de las cuatro virtudes morales, o mejor fablando cardinales, la más noble y soberana es la prudencia, después la justicia, después la fortitudo, $y$ a la fin la temperancia. ${ }^{42}$

No menos interesante para el asunto que nos ocupa es la segunda de estas cuestiones de Alfonso Fernández de Madrigal — «Si la Filosofía Moral es más útil y provechosa que la Filosofía Natural»—, ya que tras ella se esconde una de las discusiones más importantes que en ese momento se estaba viviendo en Salamanca, como ha señalado Pedro Cátedra. ${ }^{43}$ Durante siglos se dio primacía a la Filosofía Natural sobre la Filosofía Moral, y desde los orígenes de la Universidad de Salamanca, la Filosofía Natural se había considerado mucho más importante que la Moral. En su segunda quaestio el Tostado acaba concluyendo que la Filosofía Moral es mucho más útil que la Natural para la salvación del hombre, aunque antes hubiera reconocido que esta última tiene más valor en sí misma:44

E ansí paresce que la filosofía natural delante de Dios es de poco loor, y aprovecha poco o ninguna cosa para merescer el paraíso, mas antes estorba a muchos la natural; y no es así de la moral, cuyas obras aprovechan para la salvación y son necesarias, en tanto que sin ellas no nos podemos salvar, y ella nunca estorbó a la ley de Cristo, ni se podía tomar de ella algún argumento contra la fe o ley de Cristo, que cuanto la ley de Cristo es toda limpia sin mancilla. E así mandó todos los actos de virtud, como la justicia legal, que es virtud general, de la cual fabla Aristóteles, libro Ethicorum, pues concuerda la ley de Cristo con la filosofía moral, de lo cual paresce la respuesta a esta postrimera cuestión, que la filosofía moral es más fructuosa que la natural, en cuanto más aprovecha para la felicidad, a la cual non enderescamos nuestros actos todos. ${ }^{45}$

El debate debía de ser intenso ${ }^{46}$ porque después de lo dicho, y quizá para suavizar la aseveración, añade Alfonso Fernández de Madrigal a continuación: «Empero es la materia atal, que aunque se extendieran las palabras, había que examinar en ellas». Con su

42 Edición de Adolfo de Casto (Biblioteca de Autores Españoles, vol. LXV, Madrid, 1922), pág. 149.

43 Amor y Pedagogía en la Edad Media. (Estudios de doctrina amorosa y práctica literaria), Salamanca, Universidad de Salamanca-Secretariado de Publicaciones, 1989, págs. 38-39.

44 «E ansí paresce de lo susodicho que la filosofía moral es de poca certidumbre, e es de menor certidumbre que las otras ciencias, e es ella e los derechos humanales cuasi en un grado de certidumbre, por lo cual paresce que la filosofía natural es mejor e más noble o de mayor dignidad en sí misma que la filosofía moral» (edición citada, pág. 150).

45 Edición citada, pág. 152.

46 Otra prueba del alcance de esta polémica la hallamos en el Tratado de virtudes e vicios de Fernán Pérez de Guzmán, quien en el apartado dedicado a la Filosofía Natural e Moral concluye apelando a la autoridad del Tostado, posiblemente a la recogida en la obra que venimos comentando: «o porque he asaz fablado / o si no se mas dezir / aqui quiero concluyr / este presente tratado / del proçeso rrelatado / queda abierta la quistión / a la determinaçión / del gran maestro tostado» (ed. de Dorothy S. Severin,El Cancionero de Oñate-Castañeda, Madison, Hispanic Seminary of Medieval Studies, 1990, pág. 33). 
conclusión, el Tostado está preparando el camino para la implantación de la Filosofía Moral de Aristóteles en la Universidad, proceso que culminará en el siglo XVI. ${ }^{47}$

A tenor de lo visto, hemos de concluir que el interés por el tema de los vicios y las virtudes adquirió gran relevancia durante el siglo XV, ya que las numerosas traducciones de textos morales así como el tratamiento de este asunto en obras de contenido doctrinal lo ponen de manifiesto. El hecho en sí debe ser puesto en relación con la transformación que se estaba produciendo en la educación del hombre laico, pues el aumento de lectores que trajo consigo propició la difusión de este tipo de libros, entre los que también destaca la traducción castellana del Libro del tesoro de Brunetto Latini, obra enciclopédica que dedica uno de los tres libros en que se divide a la Filosofía Moral y que fue ampliamente difundida durante el siglo que nos ocupa. ${ }^{48}$ Sin duda esta nueva clase lectora formada por letrados y caballeros que imitaban las lecturas de sus señores leería con sumo agrado esta información de tipo práctico que en definitiva siempre aportaba la lectura sobre los vicios y las virtudes. Del mismo modo, el cruce entre las diversas tradiciones observado en varios textos del siglo XV prueba que la atención dedicada a este asunto superaba con creces la demostrada en otros periodos anteriores.

47 A. R. D. Pagden, «The diffusion of Aristotle's maral philosophy in Spain, ca. 1440-ca. 1600», Traditio, 31 (1975), págs. 312-313.

48 Véase Jeremy Lawrance, «The Spread of Lay Literacy in Late Medieval Castile», Bulletin of Hispanic Studies, LXII (1985), págs. 93-94. 